\title{
Comparison of Airfoil Precomputational Analysis Methods for Optimization of Wind Turbine Blades
}

\author{
Ryan Barrett \\ Brigham Young University - Provo, ryan.barrett100@gmail.com \\ Andrew Ning \\ Brigham Young University - Provo, aning@byu.edu
}

Follow this and additional works at: https://scholarsarchive.byu.edu/facpub

Part of the Mechanical Engineering Commons

\section{Original Publication Citation}

Barrett, R., and Ning, A., "Comparison of Airfoil Precomputational Analysis Methods for Optimization of Wind Turbine Blades," IEEE Transactions on Sustainable Energy, Vol. 7, No. 3, Jul. 2016, pp. 1081-1088. doi:10.1109/TSTE.2016.2522381

\section{BYU ScholarsArchive Citation}

Barrett, Ryan and Ning, Andrew, "Comparison of Airfoil Precomputational Analysis Methods for Optimization of Wind Turbine Blades" (2016). Faculty Publications. 1671.

https://scholarsarchive.byu.edu/facpub/1671

This Peer-Reviewed Article is brought to you for free and open access by BYU ScholarsArchive. It has been accepted for inclusion in Faculty Publications by an authorized administrator of BYU ScholarsArchive. For more information, please contact ellen_amatangelo@byu.edu. 


\title{
Comparison of Airfoil Precomputational Analysis Methods for Optimization of Wind Turbine Blades
}

\author{
Ryan Barrett and Andrew Ning \\ Mechanical Engineering Department \\ Brigham Young University \\ Provo, Utah 84602 \\ Email: ryan.t.barrett@byu.edu
}

\begin{abstract}
The objective of this research was to develop and compare various airfoil precomputational parameterization and analysis techniques for aerostructural optimization of wind turbine blades. The airfoils along the blade were added as optimization design variables through precomputational parameterization methods using thicknessto-chord ratios and blended airfoil family factors. The airfoils' aerodynamic performance was analyzed with three methods of increasing fidelity: a panel method (XFOIL), Navier-Stokes based computational fluid dynamics (RANS CFD), and wind tunnel data. The optimizations minimized mass over annual energy production $(m / A E P)$ and thereby approximated the minimization of cost of energy. The results were compared to the NREL 5-MW reference turbine and a conventional optimization where the airfoils were fixed. Results showed an average $m / A E P$ reduction of $1.7 \%$ over conventional optimization methods. The primary benefit in adding the airfoil shape was through an increase in annual energy production (1.6\%) with a similar decrease in turbine mass $(\mathbf{1 . 8 \%})$. Using the precomputational airfoil parameterization methods provided significant reductions in the cost of energy with relatively minor additional computational cost.
\end{abstract}

Keywords-wind power generation, blade optimization, airfoil parameterization, free-form, computational fluid dynamics (CFD), XFOIL, thickness-to-chord ratio

\section{NOMENCLATURE}

\begin{tabular}{|c|c|}
\hline$\alpha$ & angle of attack \\
\hline AEP & annual energy production \\
\hline$c_{d}$ & two-dimensional drag coefficient \\
\hline$c_{l}$ & two-dimensional lift coefficient \\
\hline CFD & computational fluid dynamics \\
\hline $\mathrm{COE}$ & cost of energy \\
\hline$m / A E P$ & total mass over annual energy production \\
\hline NREL & National Renewable Energy Laboratory \\
\hline RANS & Reynolds-averaged Navier-Stokes \\
\hline$t / c$ & thickness-to-chord ratio \\
\hline
\end{tabular}

\section{INTRODUCTION}

While wind turbines as a sustainable technology have made impressive gains in capacity and energy production in recent years, there still exists areas of improvement in terms of efficiency and cost of energy (COE). Through optimization, it is possible to increase the energy production of wind turbines and/or decrease the cost of construction and maintenance. The problem with a conventional aerostructural blade optimization, however, is that it is usually performed sequentially, where the two-dimensional airfoil shapes that compose the threedimensional wind turbine blade are often chosen before the blade is optimized [1]. Fixing the shape of the airfoils during the blade optimization process is a limitation to finding a optimal blade design. One of the major hurdles with parameterizing the entire airfoil shape, however, is the large computational cost and complexity to analyze the airfoils in the optimization loop. This research seeks to explore how various precomputational airfoil parameterization and analysis methods can contribute to reducing wind turbine's cost of energy with relatively minor computational cost.

\section{A. Background}

Conventional blade optimization consists of choosing a priori several airfoils across the blade span that remain fixed throughout the optimization, as shown in Fig. 1.

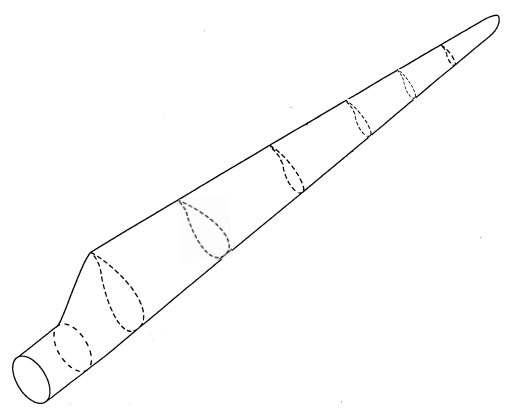

Fig. 1: Conventional approach to blade optimization with fixed airfoil shapes across the blade span. 
One weakness in leaving the airfoil shapes fixed is that the optimization fails to fully capture the tradeoffs that exist between the blade's aerodynamic performance and its structural integrity. A free-form approach parametrizes the airfoil shapes that compose the blade and adds those parameters as design variables to find a better design. Aerodynamic performance tends to improve with thinner airfoils while the blade's structural integrity tends to improve with thicker airfoils. Adding the airfoil shapes becomes especially meaningful for applications where blade performance is more sensitive to changes in airfoil shape or thickness such as in low induction rotors [2] or high tip-speed turbines [3].

The airfoil shape has generally not been added to blade optimization in the past due to the relatively large number of design variables needed and the challenge and complexity in obtaining continuous and differentiable aerodynamic performance data for the optimization loop. However, by precomputing the aerodynamic data for simple airfoil shape parameters, the airfoil shapes can still adapt to find a better design with relatively minor additional complexity. Although not as high-fidelity as the full free-form approach, precomputational parameterization methods can capture some of the benefit of the free-form design relatively easily.

\section{B. Contribution}

Prior research by Barrett et al. has explored the option of fixing the airfoil family and adding a single design variable to account for the airfoil shape: thickness-tochord ratio $(t / c)$ [4]. The results showed a reduction of $0.8 \%$ in the optimization of total turbine mass over annual energy production $(m / A E P)$ as compared to the reference turbine due to an increase in energy production and decrease in mass. While this previous approach does have the advantage of minimizing the number of design variables, it is limited in that the airfoil family was fixed and a lower-fidelity panel method (XFOIL) [5] was used to provide the aerodynamic data. Panel methods are not as accurate and have problems converging in highly separated flow. Bottasso et al. [2] also uses XFOIL in their free-form analysis, and this research extends to the higher-fidelity methods of Reynolds-averaged Navier-Stokes (RANS) computational fluid dynamics (CFD), wind tunnel data, and parameterizations to blend between airfoil families.

This research seeks to expand and contribute to prior findings in three ways:

- examine the effect of airfoil precomputational parameterization methods (i.e. $t / c$, blended family)

- explore airfoil analysis methods of increasing fidelity (i.e. XFOIL, RANS CFD, and wind tunnel)

- compare the cost of energy reduction for conventional and free-form approach to blade optimization
To achieve the desired objectives, nine optimization cases were performed as shown in Table I, allowing for direct comparisons between methods for a better understanding of their effect. This investigation contributes to wind turbines as a sustainable technology by providing methods for making wind turbine blades more costeffective and contribute to the world's energy needs.

TABLE I: Optimization Cases Summary

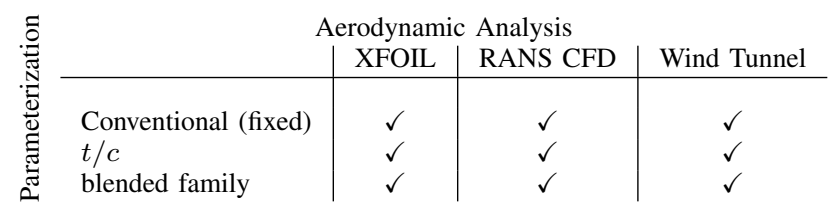

\section{Methodology}

For each optimization case, the airfoil shapes along the blade are parametrized, the aerodynamic performance precomputed, the blade analyzed with analysis tools from the National Renewable Energy Laboratory (NREL), and optimized to reduce COE.

\section{A. Airfoil Shape Parameterization}

1) Conventional method with airfoil shape fixed: To determine what additional benefit adding the airfoil shapes had over conventional aerostructural blade optimization, the blade needed to be optimized with the airfoil shapes fixed. Airfoils were chosen based on the 5MW reference turbine [6]. The design variables were the chord distribution, max chord location, twist distribution, and tip-speed ratio in Region 2.

2) Thickness-to-chord ratio $(t / c)$ : A central characteristic of an airfoil is its thickness, which affects both the blade's aerodynamics and its structural integrity. The thickness can be controlled through the thickness-tochord ratio for a fixed airfoil family.

For this case, the fixed airfoil families match those used in the NREL 5-MW reference turbine: the TU Delft for the first two-thirds and NACA 64-series for the last third of the blade span. For both of these airfoil families, eight airfoils with $t / c$ ranging from $12 \%$ to $40.5 \%$ were analyzed and the coefficients of lift and drag $\left(c_{l}\right.$ and $\left.c_{d}\right)$ were extracted at various angles of attack $(\alpha)$. Both the lift and drag coefficients were splined across $\alpha$ and $t / c$ as seen in Fig. 2. A smoothing factor of 0.01 and 0.005 was made to the lift and drag coefficient splines, respectively. The lift and drag coefficients could be estimated for any $\alpha$ and $t / c$ within the bounds for either airfoil family.

3) Thickness-to-chord ratio with blended airfoil families (blended family): As blades often do not use a single airfoil family, the airfoils in this parameterization method were given the ability to blend between airfoil families as seen in Fig. 3. 


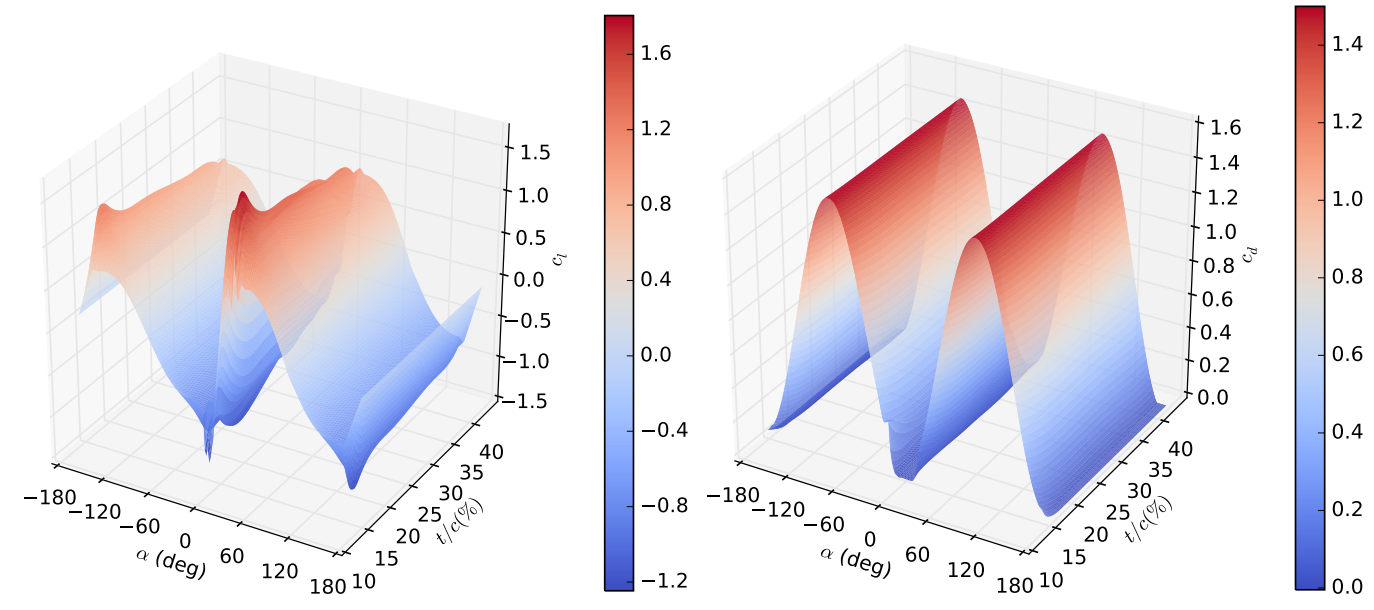

(a) 2D spline of lift coefficient based on $\alpha$ and $t / c$ (b) 2D spline of drag coefficient based on $\alpha$ and $t / c$

Fig. 2: Comparison of the lift and drag coefficient response surfaces for TU-Delft airfoil family

In the previous parameterization method of $t / c$, the airfoil family was fixed. In this method, an airfoil family blend factor is added as a design variable where a value of 0.0 corresponded to the TU-Delft family and 1.0 corresponded to the NACA 64-series family. For example, a factor of 0.3 would mean that that airfoil was $70 \%$ TU-Delft and 30\% NACA 64-series. The aerodynamic data was blended using the AirfoilPreppy blend tool [7]. The actual airfoil coordinates were blended using the FUSED-Wind geometry blend tool [8]. Both of these blending techniques are based on a linear interpolation.

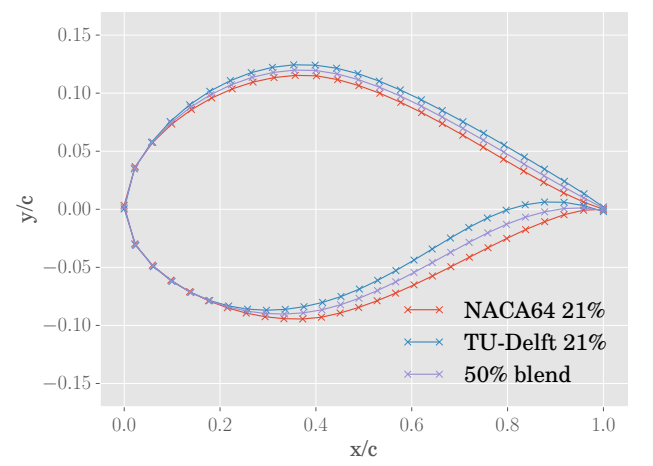

Fig. 3: Comparison of blended airfoil for $t / c$ of $21 \%$.

\section{B. Aerodynamic Analysis}

With the airfoil shape parametrized, the lift and drag coefficients were estimated in order to calculate the annual energy production of the blade. There are many techniques to do this, but the following methods were used of increasing fidelity: XFOIL, RANS CFD, and wind tunnel data. As previous research has most commonly analyzed the aerodynamic performance of the blade's airfoils using XFOIL [9], [10], [4], using higherfidelity techniques such as RANS CFD or wind tunnel data was warranted to obtain more accurate results. A comparison of the aerodynamic performance of an airfoil using XFOIL, RANS CFD, and known wind tunnel data is shown in Fig. 4. As seen in the figure, the RANS CFD data more closely matches the known wind tunnel data as compared to XFOIL, especially post-stall.

1) XFOIL Aerodynamic Analysis: XFOIL is a software program developed by Drela that uses a linear potential (panel) method in the design and analysis of subsonic isolated airfoils [5]. Given the 2D coordinates from the airfoil parameterization, XFOIL performs an aerodynamic computational analysis and calculates the pressure distribution and thereby $c_{l}$ and $c_{d}$. The XFOIL analysis was performed with the airfoils of various $t / c$ ratios for angles of attack from $-20^{\circ}$ to $20^{\circ}$ with a Reynolds number of $10^{6}$ and $N_{\text {crit }}$ of 9 (corresponding to the turbulence of an average wind tunnel). The advantage of XFOIL is that it performs the analysis very quickly. The disadvantage of XFOIL, however, is that since it is based on idealized computational models, XFOIL tends to under-predict drag coefficients and slightly over-predict lift coefficients. The angle of attack and shape parameters were tightly bounded so as to reduce the likelihood of non-convergence from highly separated flow. 


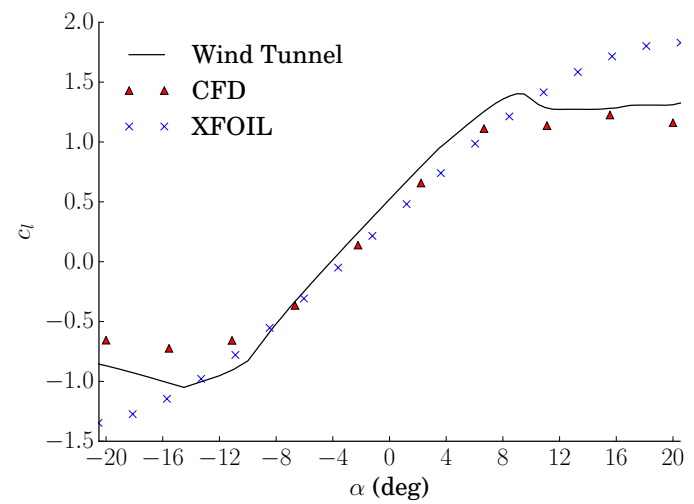

(a) $c_{l}$ versus $\alpha$

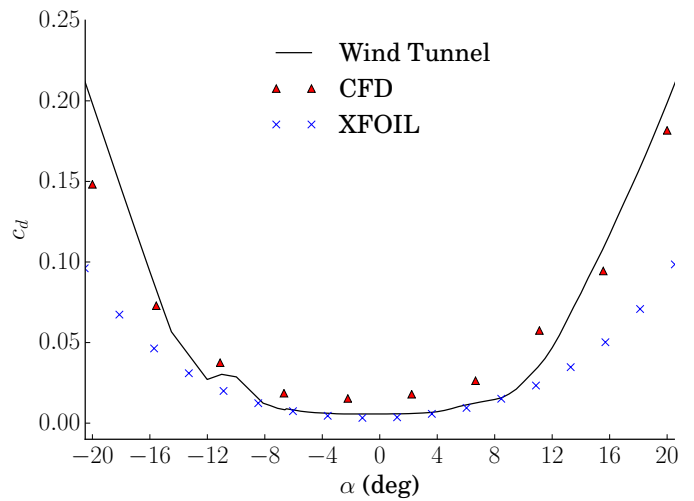

(b) $c_{d}$ versus $\alpha$

Fig. 4: Comparison of airfoil analysis techniques (XFOIL vs. RANS CFD vs. Wind Tunnel) for the DU21_A17 airfoil with a Reynolds number of $1 \times 10^{6}$

2) RANS CFD Aerodynamic Analysis: To more accurately predict the lift and drag coefficients, CFD software was used. Due to the ability to script in Python and obtain adjoint gradients, the open-source CFD software package $S U 2$ by Stanford University was used [11].

One of the most important aspects of an accurate CFD code is the mesh. However, a major challenge in using CFD to optimize is that the necessary mesh is often not known beforehand. A mesh deformation tool was adapted from the educational version of $S U 2$ [11] and provided the capability to generate any airfoil mesh as needed. The mesh consisted of 14,000 cells as seen in Fig. 5 with two boundaries at the airfoil surface and the far-field placed 40 chord lengths away from the airfoil.

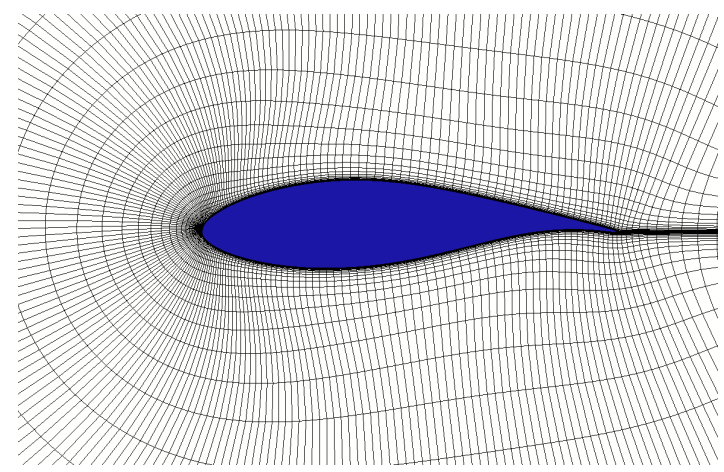

Fig. 5: DU21_A17 airfoil C-mesh near-field created with $S U 2$ mesh deformation tool

The mesh was analyzed using $S U 2$ software with an incompressible Reynolds-averaged Navier-Stokes (RANS) method to account for viscous effects with the one-equation Spalart-Allmaras turbulence model. The convergence criteria specified a residual change of $10^{-10}$ with a maximum number of iterations of 20,000.
3) Wind Tunnel Aerodynamic Analysis: Although wind tunnel data is the highest-fidelity data most commonly used for analysis, obtaining the data is difficult, expensive, and time-consuming. As each airfoil would need to be built and analyzed in a wind tunnel, it would be difficult (if not impossible) to use in a full free-form approach. Nevertheless, the aforementioned methods could be used because wind tunnel data is available for the airfoils used in the 5-MW turbine.

While wind tunnel data was known for most thicknessto-chord ratios, when not available a correction was applied to XFOIL data to mimic wind tunnel data. The XFOIL data was corrected instead of the RANS CFD data because of its speed and because only few corrections were needed. Wind tunnel data was known for five thickness-to-chord ratios ranging from $21 \%$ to $40 \%$. XFOIL was calculated at those same five thicknessto-chord ratios and the difference between the $c_{l}$ and $c_{d}$ for the wind tunnel and XFOIL were taken and averaged at each angle of attack. For the lower thickness-to-chord ratios where wind tunnel data was not available, XFOIL was used and then the correction applied so that the data would more closely match the wind tunnel data. The XFOIL correction is therefore a drag and lift offset based on the known difference between the wind tunnel and computational data under the same conditions.

For example, Fig. 6 shows a combined lift and drag correction for lift over drag (although the correction was applied to each separately) at an angle of attack of $5.0^{\circ}$ for the TU Delft airfoil family. The wind tunnel data was used for most of the analysis and the corrected XFOIL data was used for the smaller thickness-to-chord ratios where wind tunnel data was not available. Therefore, the lift and drag coefficients were anchored with wind tunnel data and augmented with corrected XFOIL data. 


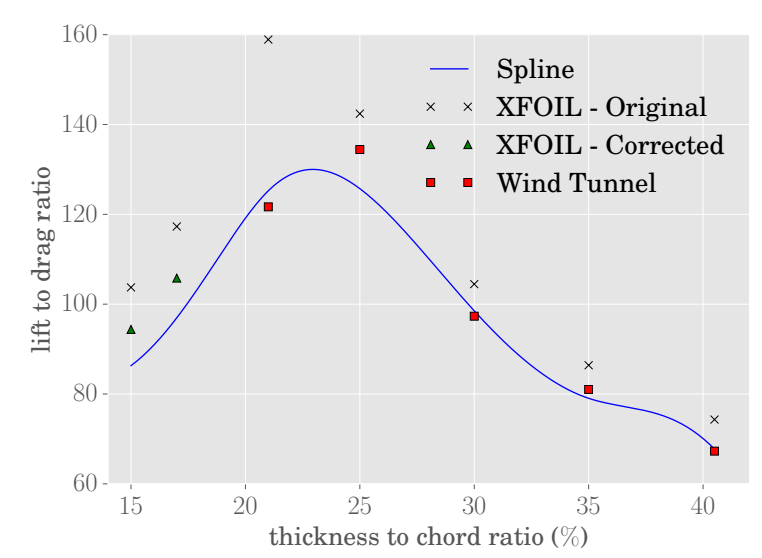

Fig. 6: Wind tunnel with corrected XFOIL at $\alpha=5.0^{\circ}$

\section{Blade Analysis}

The lift and drag coefficients from the aerodynamic analysis were rotational corrected and extrapolated using the AirfoilPreppy Python tool to prepare for blade analysis [7]. The 3D rotational corrections were performed using Du's method [12] to augment the lift and Eggers' method [13] to modify the drag. The Viterna method [14] was used to extrapolate the lift and drag coefficients from $-180^{\circ}$ to $180^{\circ}$ for use in the blade analysis.

A blade element momentum method with guaranteed convergence (CCBlade) [15] within the wind blade analysis tool RotorSE [16] was used for the blade analysis. The airfoil coordinates of the different airfoils were input the structural analysis as profile sections. Standard IEC specifications for a land-based high-wind-speed site (IEC Class IB) were used corresponding to a mean wind speed of $10.0 \mathrm{~m} / \mathrm{s}$ [17]. The wind conditions followed a Weibull distribution with a shape parameter of 2.0. The aerodynamics of the blade must trade-off with the internal blade structures to withstand the loads and stresses during use. The major sources of structural integrity are composite panels in the spar cap, web, and trailing edge. The layers include GelCoat, glass fabrics, SNL TRAIX, SaerTex Double Dias, carbon fabrics, generic foam, and epoxy resins [18]. Changes in the chord and airfoil shape result in changes to these structural composite layers.

\section{Optimization}

While COE is the ultimate goal of wind turbine optimization, optimizing for the $m / A E P$ approximates COE as shown by Ning et al. for fixed diameter rotors [18]. Since the rotor diameter was fixed and the total turbine mass (including the blades, hub, nacelle, and tower) was used, minimizing $m / A E P$ was a reasonable approximation for minimizing $\mathrm{COE}$ as the mass of the turbine is approximately proportional to its cost. The reduction in $m / A E P$ is achieved by increasing annual energy production (AEP) and reducing the blade mass.

In total, nine optimization cases were performed and compared using the three parameterizations (conventional, $t / c$, and blended family) and three analysis methods (XFOIL, CFD, and wind tunnel). This allowed direct comparisons between the different airfoil parameterization and analysis techniques. The relevant design variables in each case are summarized in Table 1. Several of these variables define control points on a spline that construe the entire blade. These design variables are explained in more detail by Ning et al. [18].

TABLE II: Number of Design Variables Summary

\begin{tabular}{lllll}
\hline Optimization Technique & & Conven. & $t / c$ & blended family \\
\hline chord distribution & $c_{i}$ & 4 & 4 & 4 \\
max chord location & $\mathrm{r}_{-} \mathrm{c}$ & 1 & 1 & 1 \\
twist distribution & $\theta_{i}$ & 4 & 4 & 4 \\
tip-speed ratio & $\lambda$ & 1 & 1 & 1 \\
thickness-to-chord ratio & $t / c_{i}$ & - & 6 & 6 \\
airfoil blend factor & $a f_{i}$ & - & - & 6 \\
\hline total \# & & 10 & 16 & 22 \\
\hline
\end{tabular}

There were a number of constraints on the optimization to ensure the blade could withstand the stresses and strains that it experiences during operation. The categories include constraints on the strain and buckling of the spar cap and trailing edge, the flap-wise and edge-wise frequency, and the rotor thrust. The strain was constrained for extreme load conditions according to IEC standards. The buckling was constrained for maximum operating conditions. All natural frequencies had to be above the blade natural frequency with an added margin to avoid resonance. While only the mass of the blades could change as part of the optimization, the calculation of the $m / A E P$ included the entire system mass for the $\mathrm{COE}$ to be best approximated. For the $m / A E P$ approximation to be reasonable, the rotor thrust had to be fixed to conservatively neglect the impact on the tower and the drivetrain mass and the rated power was kept constant at 5-MW. Additional detail on these constraints is described by Ning et al. [18].

The optimization was performed using a gradientbased sequential quadratic programming method called the Sparse Nonlinear OPTimizer (SNOPT) [19] optimization package within the OpenMDAO [20] framework for multidisciplinary optimization. All of the design variables were scaled to be of a similar magnitude.

\section{RESULtS}

The optimization was performed for each combination of airfoil analysis and parameterization method. The results are all compared to the NREL 5-MW reference turbine evaluated with that airfoil analysis technique (i.e., the XFOIL reference blade was evaluated using XFOIL, 


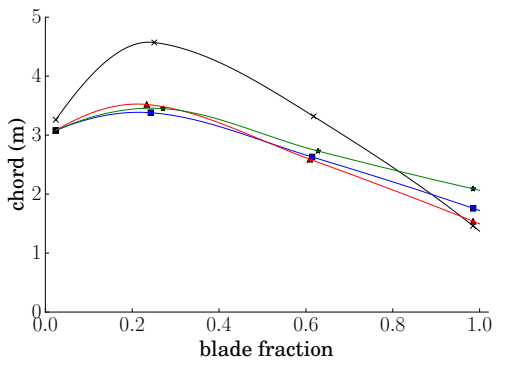

(a) XFOIL - Chord

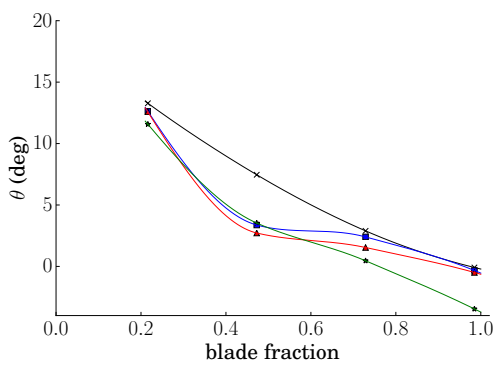

(d) XFOIL - Twist

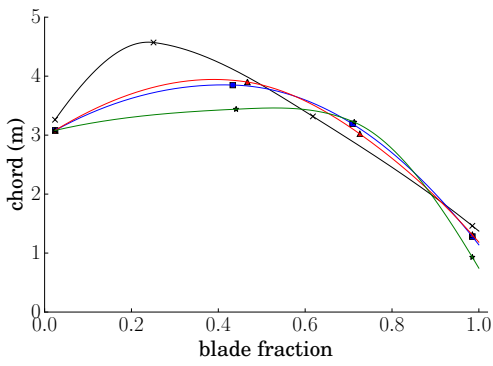

(b) CFD - Chord

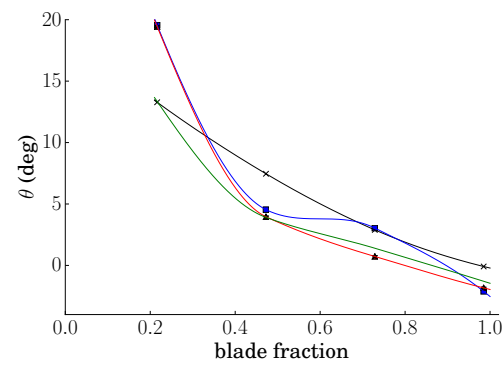

(e) CFD - Twist

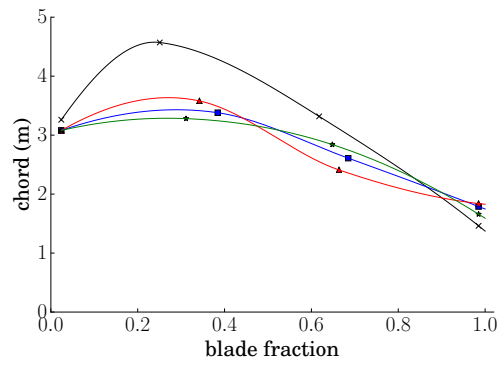

(c) Wind Tunnel - Chord

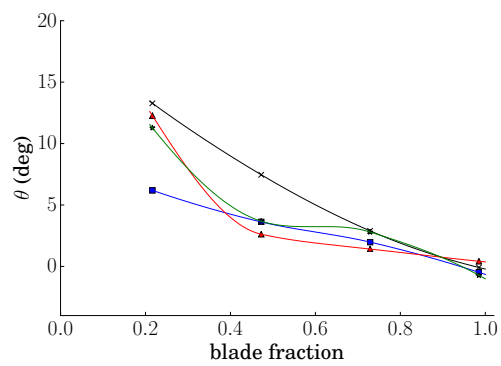

(f) Wind Tunnel - Twist

Fig. 7: Chord and twist distribution comparisons

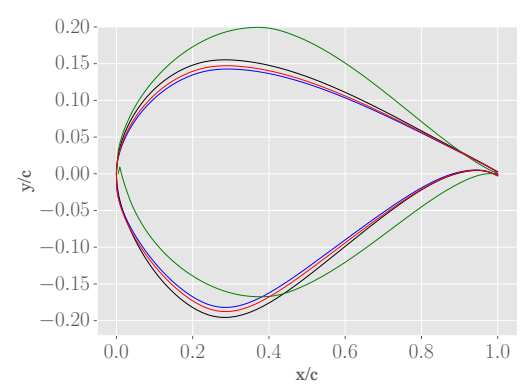

(a) blade fraction $=0.258$

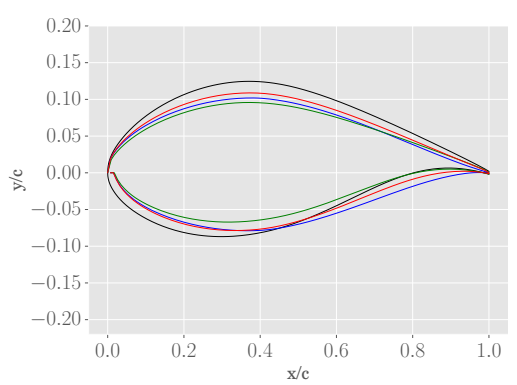

(b) blade fraction $=0.658$

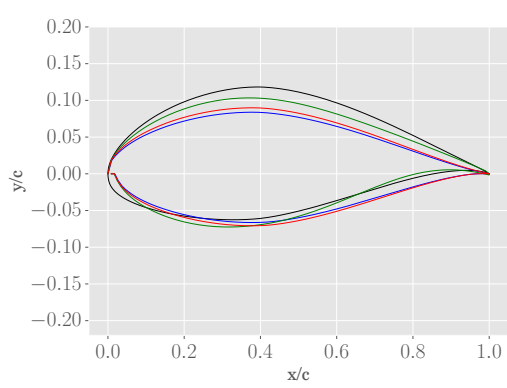

(c) blade fraction $=1.0$

\section{- Reference - XFOIL - CFD - Wind Tunnel}

Fig. 8: Blended family airfoil shape results

the CFD reference blade was evaluated using CFD) with conventional, $t / c$, and blended family methods ${ }^{1}$. A comparison of the chord and twist is shown in Fig. 7 and several airfoil shapes along the blade span are shown in Fig. 8. There was an average further $m / A E P$ reduction of $0.9 \%$ for the $t / c$ method and $1.7 \%$ for the blended family method over the conventional cases.

\section{A. XFOIL}

With XFOIL as the aerodynamic analysis, increasing the parameterization degrees of freedom significantly

\footnotetext{
${ }^{1}$ The full optimization results for each of the design variables can be found at http://flow.byu.edu/publications.
}

reduced $m / A E P(-1.4 \%,-2.4 \%$, and $-4.0 \%$ for the conventional, $t / c$, and blended family respectively). While the total mass reduction was similar in all cases $(-2.1 \%$, $-2.3 \%,-2.1 \%)$, the main difference was in AEP. The conventional case actually reduced AEP (-0.8\%) while adding the airfoil shape allowed the AEP to increase $(+0.2 \%$ and $+2.1 \%$ for $t / c$ and blended family respectively). The main area of mass reduction was with decreasing the chord and using thinner airfoils. The chord decreased on average by $14.0 \%, 15.0 \%$, and $10.0 \%$ respectively. The twist also decreased in all three cases on average by $21.1 \%, 27.0 \%$, and $19.8 \%$ respectively. The tip-speed ratio in Region 2 in all three cases increased as 
well by $12.2 \%, 4.2 \%$, and $7.3 \%$ respectively. The shape of the airfoils along the blade changed significantly and in almost all cases were thinner by an average of $-3.5 \%$ for $t / c$ and $-5.9 \%$ for the blended family. When the airfoil family was allowed to change, the blade near the tip became more NACA 64-series type.

\section{B. RANS CFD}

Using CFD as the aerodynamic analysis, the $m / A E P$ was significantly reduced $(-4.0 \%,-4.5 \%$, and $-5.1 \%$ for the conventional, $t / c$, and blended family respectively). Just like with XFOIL, the total mass reduction was similar in all cases $(-1.0 \%,-1.0 \%,-1.7 \%)$ and the main difference was in AEP. Increasing the degrees of freedom of the airfoil parameterization increased the amount that the AEP was able to increase $(+3.1 \%,+3.4 \%,+3.6 \%)$. The chord decreased on average by $9.6 \%, 10.3 \%$, and $15.4 \%$ respectively. The twist increased by $23.3 \%$ and $9.4 \%$ for the conventional and $t / c$, but decreased by $15.9 \%$ for the blended family. The tip-speed ratio decreased by $2.3 \%, 2.3 \%$, and $6.9 \%$ respectively. The shape of the airfoils along the blade were also thinner but less so than with XFOIL by an average of $-2.1 \%$ for $t / c$ and $-1.9 \%$ for the blended family. When the airfoil family was able to change in the blended family method, the blade became much more NACA 64-series type near the root and much less so near the tip.

\section{Wind Tunnel}

Using wind tunnel data as the aerodynamic analysis, the $m / A E P$ was significantly reduced $(-2.4 \%,-3.3 \%$, and $-3.7 \%$ for the conventional, $t / c$, and blended family respectively). Just like with XFOIL and CFD, the total mass reduction was similar in all cases $(-2.1 \%,-2.2 \%$, $-2.0 \%)$ and the main difference was in AEP. Increasing the degrees of freedom of the airfoil parameterization increased the amount that the AEP was able to increase $(+0.3 \%,+1.2 \%,+1.8 \%)$. The chord decreased on average by $13.9 \%, 13.5 \%$, and $13.9 \%$ respectively. Like XFOIL, the twist decreased in all three cases on average by $48.3 \%, 33.0 \%$, and $22.1 \%$ respectively. The tip-speed ratio changed by $+6.6 \%,+6.2 \%$, and $+12.5 \%$ respectively. The shape of the airfoils along the blade were also thinner but more similar to CFD with an average change of $-3.8 \%$ for $t / c$ and $-2.6 \%$ for the blended family. For the blended family, the blade became more NACA 64series style from about the center to the tip of the blade as compared to the original 5-MW reference turbine.

\section{Discussion}

Adding the airfoil shape produced improved results over the sequential design with the airfoils fixed and resulted in different blade designs. The trade-offs between the aerodynamic performance of the blade and the needed structural thickness are better explored by the optimization as a result. Table III shows a summary of the reduction in $m / A E P$ for the nine optimizations.

TABLE III: Results Summary - $m / A E P$ Reduction

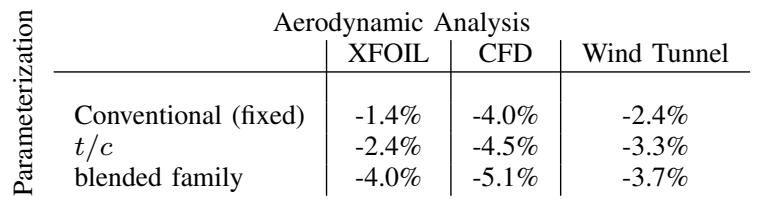

\section{A. Effect of Airfoil Parameterization}

The main takeaway is that a significant benefit can be gained through precomputational parameterization methods with minimal computational cost and complexity. Additional degrees of freedom in the airfoil parameterization allow for a greater increases in AEP, the primary source of $m / A E P$ reduction. There were minimal changes in mass reduction when the aerodynamic analysis was fixed. The average increase in AEP for $t / c$ over the conventional case was $0.7 \%$. The average increase in AEP for blended family was $1.6 \%$ over the conventional case and $0.9 \%$ over the $t / c$. Both parameterization methods had a similar effect on reducing $m / A E P$.

While the airfoil parameterization had a significant effect on the optimal airfoil shapes, it had minimal impact on the other design variables. The chord, twist, and tip-speed ratio experienced small changes between parameterization methods, in contrast to the large impact on the optimal design between analysis methods.

\section{B. Effect of Aerodynamic Analysis}

While the overall reduction in $m / A E P$ between the various aerodynamic analysis cases were similar, the optimal blade design actually changed significantly in terms of airfoil shape, chord, twist, etc. and is therefore quite sensitive to airfoil analysis method. This alludes to the idea that while high-fidelity data is always recommended if possible, it is particularly important in a free-form blade optimization.

\section{General Insight}

Adding the airfoil shape in this general case of wind turbine blade optimization showed a modest but important improvement in reducing COE. The improvement is likely to be greater with more specific applications such as high tip-speed rotors, alluded to because in most of the optimization cases the tip-speed ratio increased. Although the overall mass decreased, the composite ply 
thicknesses that make up the spar cap and trailing edge composite panels in the blade structures increased to offset the decreases in the chord distribution and the thickness-to-chord ratios.

The implication that the blade design is quite robust to changes in airfoil parameterization suggests that an extended sequential blade design might be adequate in some cases. The airfoils could be chosen and the blade optimized and then the airfoils could be re-optimized. Regardless, there were slight but significant changes in optimal blade design and performance with different airfoil parameterization techniques. While a full free-form design needs to be performed for direct comparisons, it appears that a large portion of the benefit from free-form design can be captured through a fewer number of design variables using precomputational parameterization methods. Other precomputational parameterization methods could include blending more than two airfoil families, camber, etc. A free-form approach could have a significant impact in making wind energy a more appealing energy source due to increased energy production with similar reductions in cost/mass.

\section{CONCLUSION}

From this analysis, there is an increased ability to balance the trade-offs between aerodynamic and structural design of turbine blades. The results show the potential of performing precomputational parameterization methods to improve the performance of wind turbine blades with minor additional computational cost and complexity. Increasing the degrees of freedom for airfoil parameterization techniques had a significant improvement on reducing the $m / A E P$ primarily by increasing AEP. Adding $t / c$ resulted in a $0.9 \%$ further reduction in $m / A E P$ over conventional methods and the blended airfoil family factor had a $1.7 \%$ further reduction. The airfoil aerodynamic analysis method had a large impact on the optimal blade design and suggests the importance of high-fidelity data. It is recommended, where applicable, that the airfoil shape be added through design variables to wind turbine blade optimization so as to further reduce the cost of energy.

Additional work, including investigations into high tip-speed turbines and a full cost of energy analysis, could be performed to further increase the applicability and fidelity of these results. More research is needed into the possibility of an extended sequential blade design where the airfoils are re-optimized. Future Work into the full free-form method would help increase the method's accuracy and capability and the trade-offs between computational cost and fidelity could be better explored. Integrating the free-form approach into existing tools would allow this capability to be more readily used in other academic and industrial applications.

\section{REFERENCES}

[1] K. Chen and P. Chen, "Structural optimization of $3 \mathrm{MW}$ wind turbine blades using a two-step procedure," Int. J. Simul. Multidisci. Des. Optim., vol. 4, no. 3, 2010.

[2] C. L. Bottasso, A. Croce, and L. Sartori, "Free-form design of low induction rotors," AIAA SciTech, 2015.

[3] K. Dykes, A. Ning, R. King, P. Graf, G. Scott, and P. Veers, "Sensitivity analysis of wind plant performance to key turbine design parameters: A systems engineering approach," in 32nd ASME Wind Energy Symposium, National Harbor, Maryland, January 2014.

[4] R. Barrett, I. Freeman, and A. Ning, "Effect of airfoil and composite layer thicknesses on an aerostructural blade optimization for wind turbines," in IEEE Conference on Technologies for Sustainability, Ogden, UT, July 2015.

[5] M. Drela, "XFOIL: An analysis and design system for low reynolds number airfoils," in Low Reynolds Number Aerodynamics, ser. Lecture Notes in Engineering, T. Mueller, Ed. Springer Berlin Heidelberg, 1989, vol. 54, pp. 1-12.

[6] J. M. Jonkman, S. Butterfield, W. Musial, and G. Scott, Definition of a 5-MW reference wind turbine for offshore system development. National Renewable Energy Laboratory Golden, CO, 2009.

[7] A. Ning, "NREL WISDEM Airfoilpreppy." [Online]. Available: http://wisdem.github.io/AirfoilPreppy

[8] F. Zahle, "FUSED Wind - airfoil and blade geometry." [Online]. Available: http://fusedwind.org/turbine_structure.html

[9] C. Bottasso, A. Croce, L. Sartori, and F. Grasso, "Free-form design of rotor blades," in Journal of Physics: Conference Series, vol. 524, no. 1. IOP Publishing, 2014, p. 012041.

[10] G. Kenway and J. Martins, "Aerostructural shape optimization of wind turbine blades considering site-specific winds," in Proceedings of the 12th AIAA/ISSMO Multidisciplinary Analysis and Optimization Conference, Sept, 2008, pp. 10-12.

[11] F. Palacios, M. R. Colonno, A. C. Aranake, A. Campos, S. R. Copeland, T. D. Economon, A. K. Lonkar, T. W. Lukaczyk, T. W. Taylor, and J. J. Alonso, "Stanford University Unstructured (SU2): An open-source integrated computational environment for multi-physics simulation and design," AIAA Paper, vol. 287, p. 2013, 2013.

[12] Z. Du and M. S. Selig, "A 3-D stall-delay model for horizontal axis wind turbine performance prediction," AIAA Paper, vol. 21, 1998.

[13] A. Eggers, K. Chaney, and R. Digumarthi, "An assessment of approximate modeling of aerodynamic loads on the uae rotor," in ASME 2003 Wind Energy Symposium. American Society of Mechanical Engineers, 2003, pp. 283-292.

[14] L. A. Viterna and D. C. Janetzke, "Theoretical and experimental power from large horizontal-axis wind turbines," National Aeronautics and Space Administration, Cleveland, $\mathrm{OH}$ (USA). Lewis Research Center, Tech. Rep., 1982.

[15] A. Ning, "A simple solution method for the blade element momentum equations with guaranteed convergence," Wind Energy, vol. 17, no. 9, pp. 1327-1345, 2014.

[16] A. Ning, "NREL WISDEM RotorSE." [Online]. Available: http://wisdem.github.io/RotorSE/

[17] European Committee for Standardisation, "Eurocode 3: Design of steel structures-part 1-6: General rules-supplementary rules for the shell structures," European Committee for Standardisation, EN 1993-1-6: 20xx, 1993.

[18] A. Ning, R. Damiani, and P. J. Moriarty, "Objectives and constraints for wind turbine optimization," Journal of Solar Energy Engineering, vol. 136, no. 4, pp. 04 010-041 010, June 2014.

[19] P. E. Gill, W. Murray, and M. A. Saunders, "SNOPT: An SQP algorithm for large-scale constrained optimization," SIAM Journal on Optimization, vol. 12, no. 4, pp. 979-1006, 2002.

[20] J. S. Gray, K. T. Moore, and B. A. Naylor, "OpenMDAO: An Open Source Framework for Multidisciplinary Analysis and Optimization," in 13th AIAA/ISSMO Multidisciplinary Analysis and Optimization Conference, Fort Worth, TX, AIAA, AIAA-20109101. Fort Worth, Texas: AIAA, August 2010. 